\title{
Dry deposition of particulate Cs-134 to several leafy vegetable species and comparison to deposition of gaseous Radioiodine
}

\author{
J. Tschiersch ${ }^{1}$, T. Shinonaga ${ }^{1}{ }^{1 *}$ and H. Heuberger ${ }^{2}$ \\ ${ }^{1}$ GSF-National Research Center for Environment and Health, Institute of Radiation \\ Protection, 85764 Neuherberg, Germany \\ *Present address: IAEA Laboratories, 2444 Seibersdorf, Austria \\ ${ }^{2} \mathrm{TU}$ München-Weihenstephan, Chair of Vegetable Science, 85350 Freising, Germany
}

\begin{abstract}
The dry deposition to several leafy vegetables (endive, head lettuce, red oak leaf lettuce, spinach) was studied. Particles with attached ${ }^{134} \mathrm{Cs}$ were used for testing the particulate deposition, gaseous elemental ${ }^{131}$ I was the tracer for gas deposition. The particle deposition was the highest for rough and structured leafs as red oak leaf lettuce has, but as well for spinach with many open stomata. The stomatal uptake seamed to be the most important process for gas deposition, the deposition to spinach was for Radioiodine the highest as compared to all other species. The lowest deposition was always found to the closed heads of head lettuce. The difference in deposition to the various species was up to a factor 9 .
\end{abstract}

\section{INTRODUCTION}

For the quantitative estimation of the Radiocaesium and Radioiodine contamination of vegetable foods after a nuclear accident, leafy vegetables are used as reference plants. The amount of the dry deposition of particulate radionuclides (e.g. ${ }^{134} \mathrm{Cs}$ ) and gaseous radionuclides (e.g. elemental ${ }^{131} \mathrm{I}$ ) to leafy vegetable, however, varies largely because of the different habit, surface texture and leaf uptake of the different plant species. To improve the power of prognosis in radio-ecological models, this study was performed to obtain comparative data on the deposition to various species.

In the literature many experiments on dry deposition are described. They refer mostly to the deposition onto smooth surfaces, grass and trees. Surveys of the obtained results can be found in $[1,2]$, where a high variability of the deposition is reported. For deposition of particles, a dependence on the particle size was found, with the minimum of deposition in the size range 0.1-1 $\mu \mathrm{m}$ particle diameter. This is as well the size range of an aged atmospheric aerosol and the observed Chernobyl aerosol at some distance from the source [3]. For leafy vegetables only few experimental data are available. Watterson and Nicholson [4] showed in their experiments on deposition to head lettuce an increase of deposition with increasing particle size, Wedding et al. [5] found in their study with single leafs that deposition to structured leafs covered with fine hairs is 10times higher than deposition to smooth, wax covered leafs. The deposition of Radioiodine is dependant on its chemical form. Heinemann and Vogt [6] measured for elemental $I_{2}$ up to 2 orders of magnitude higher deposition velocities compared to organic Iodine and 20 times higher velocities compared to particulate Iodine. Nakamura and Ohmoho [7,8] affirmed these results for spinach and Muramatsu et al. [9] for rice plants. Comparative deposition measurements to leafy vegetables are not available so far.

Therefore an experiment was designed in which leafy vegetables can be exposed simultaneously an atmosphere with particulate Radiocaesium and gaseous Radioiodine. To obtain well defined conditions, a monodisperse aerosol had be emitted into the deposition chamber and the physical-chemical form of Radioiodine had to be dominated by the gaseous elemental Iodine which is depositing the most effective. 


\section{METHODS}

For the exposure of several leafy vegetables with the radionuclides a large deposition chamber was constructed. In this chamber the control of the particulate ${ }^{134} \mathrm{Cs}$ and of the gaseous ${ }^{131} \mathrm{I}$ was possible during the whole exposure time of the plants.

\subsection{Exposure experiment}

To be able to expose at the same time a large number of leafy vegetables, a deposition chamber of the dimensions $4.0 \mathrm{~m} \times 1.8 \mathrm{~m} \times 1.9 \mathrm{~m}$ was set up (cross section see Fig. 1). In this chamber was space for in total 80 plant containers. Four different species were grouped in patches of mature plants. In Table 1 the species are given with their botanical names. The large plant collectives made possible a statistical analysis of the experiments. The major plant parameters were determined; these were fresh weight, dry weight, leaf area, leaf area index and conductance of water vapour diffusion. The chamber conditions as air temperature, air humidity, $\mathrm{CO}_{2}$-concentration and light intensity were such that the plant physiology was not negative effected, e.g. the plant stomata were open during day time.

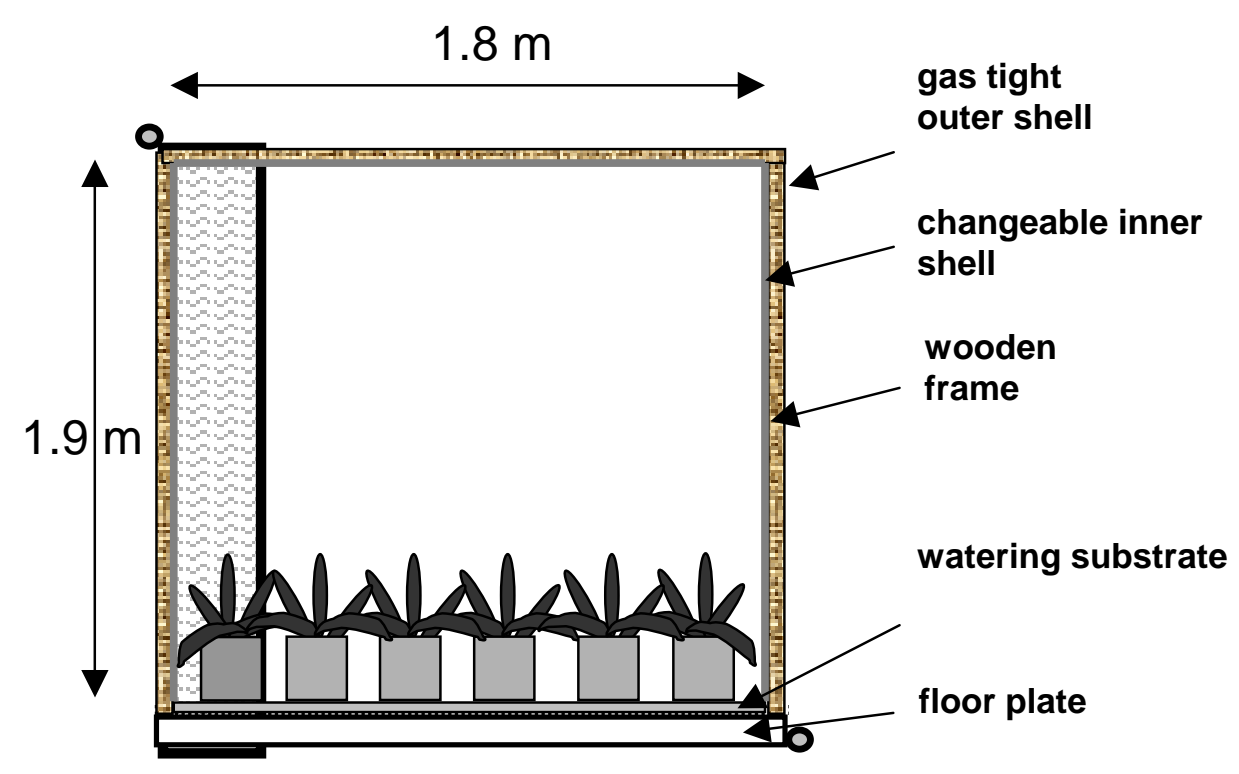

Figure 1. Cross section of the deposition chamber with an area for plant exposure of $7.2 \mathrm{~m}^{2}$.

Table 1. Exposed plants in the spring leafy vegetable experiment.

\begin{tabular}{|l|l|l|}
\hline Plant species & Botanical name & Variety (Grower) \\
\hline Spinach & Spinacia oleracea L. & Poncho (Enza) \\
\hline Head lettuce & Lactuca sativa L. var. capitata L. & E 136310 (Enza) \\
\hline Red oak leaf lettuce & Lactuca sativa L. var. crispa L. & Red Salad Bowl (Hild) \\
\hline Endive & Cichorium endivia L. & Nuance (Enza) \\
\hline
\end{tabular}


In the deposition experiment simultaneously 20 plant containers of each species given in Table1 were exposed to an atmosphere homogeneously contaminated with Radioiodine. After an exposure period of four hours Radiocaesium was homogeneously added to the atmosphere. One day after the start of the exposure, the plants were harvested and immediately prepared for $\gamma$-spectrometric analysis.

\subsection{Production and Control of particulate Radiocaesium}

Because of the above mentioned size dependence of the deposition process, the exposure experiment was performed with monodisperse aerosol. The activity median diameter of the radioactive aerosol was chosen to be close to the Chernobyl aerosol of about $0.8 \mu \mathrm{m}$ [3]. Polystyrene-latex particles of $0.8 \mu \mathrm{m}$ diameter were used as carrier aerosol. ${ }^{134} \mathrm{Cs}$ was fixed on the surface of these particles by a Cs-selective ligand, calix(4)crown-6, how it is described by Casnati et al. [10]. The particles were dispersed from a suspension by an aerosol generator (see Fig. 2).

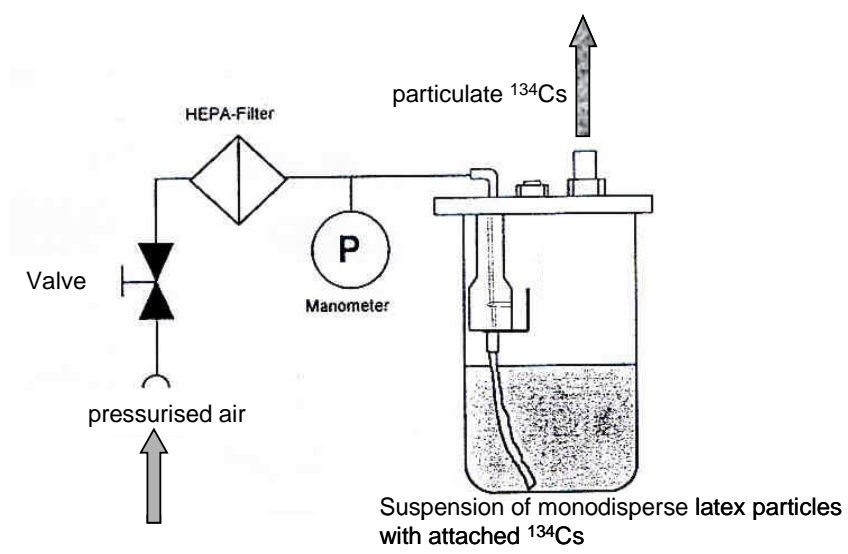

Figure 2. Aerosol generator (ATM 230, TOPAS GmbH, Dresden, Germany) dispersing ${ }^{134} \mathrm{Cs}$ labelled latex particles.

The size distribution of the ${ }^{134} \mathrm{Cs}$ particles inside the chamber was measured by particle sampling with a Berner cascade impactor [11] and $\gamma$-spectrometry. The obtained distribution (Fig. 3) has the activity median at $0.72 \mu \mathrm{m}$, the geometric standard deviation is 1.8 , in good agreement with the nominal value of the carrier aerosol. The concentration of ${ }^{134} \mathrm{Cs}$ inside the chamber was monitored by filter sampling. From the time course of the concentration, the integral air concentration can be calculated.

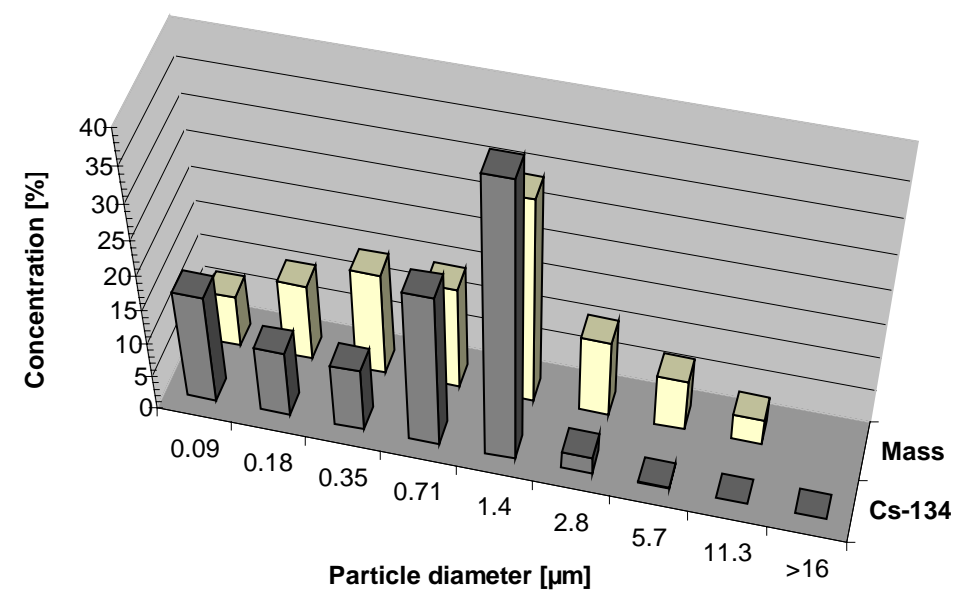

Figure 3. Activity and mass size distribution of the chamber aerosol. 


\subsection{Production and Control of gaseous Radioiodine}

Radioiodine was released as elemental ${ }^{131} \mathrm{I}_{2}$ into the chamber. The iodine gas inside the chamber was controlled for its physical-chemical composition. In the spring vegetable experiment $85.9 \%$ of the Radioiodine remained elemental, $12.7 \%$ changed to the organic form, $1.4 \%$ attached to particles. Details can be found elsewhere [12].

\section{RESULTS}

The measured activity concentrations on the plants (related to the fresh weight) were analysed with the non-parametric Kruskal-Wallis test, whether the median of one species is significant different from the other species and with the U-test (Mann-Whitney) on the significance of the difference between single species. It can be seen from Fig. 4 a), that the deposition of ${ }^{134} \mathrm{Cs}$ to red oak leaf lettuce is the highest but not significantly different to the deposition to spinach. The deposition to head lettuce is significantly the lowest, Endive is statistically well separated in the middle. For the species identified being significant different, the relation between the activity concentration of single plants was calculated for 200 randomly selected combinations. Then it was possible to set up a ranking list of these activity relations and to determine by tabulated rank positions median and range of confidence [13]. The advantage of this non-parametric ranking procedure is the independence of any assumed distribution of the measured data, the insensitivity to possible single extreme values and the determination of the confidence range.

The relations of the deposition to the spring leafy vegetable, which were determined in such a way, are given in Table 2. If we relate the deposition to the most effective species in deposition, the following order is valid:

$$
\text { A Spinach, Red oak leaf lettuce (1) > A Endive (0.58) > } A_{\text {Head lettuce }}(0.31) \text {. }
$$

This means that spinach and red oak leaf lettuce is nearly twice as highly contaminated as endive and more than 3times as highly as head lettuce at the same airborne concentration.

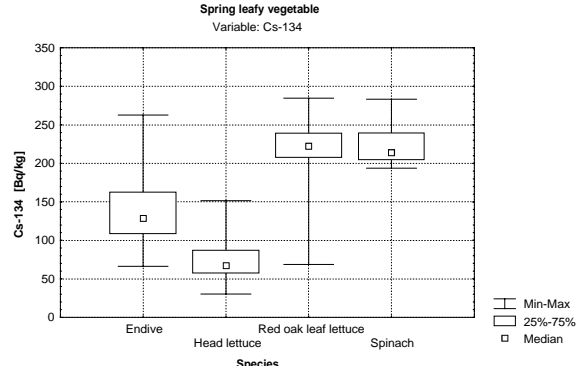

a)

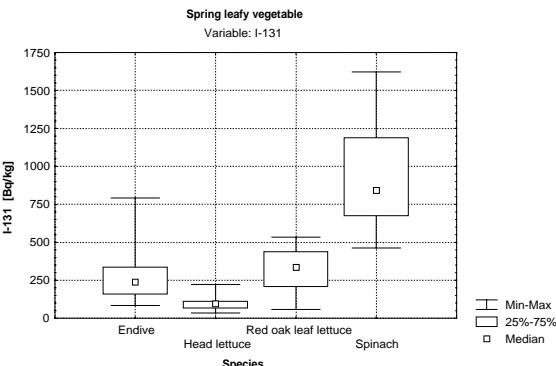

b)

Figure 4. Median and range of measured variability of deposition to spring leafy vegetable species for a) particulate ${ }^{134} \mathrm{Cs}$ and b) gaseous ${ }^{131} \mathrm{I}$.

Table 2. Relation of the activity concentration deposited on the spring leafy vegetables. Only for statistically significant different deposition, the relation was determined according the procedure explained in the text.

\begin{tabular}{|c|c|c|c|c|c|c|}
\hline Spring experiment & \multicolumn{3}{|c|}{${ }^{134}$ Cs } & \multicolumn{3}{c|}{${ }^{131}$ I } \\
\hline & Median - $\sigma$ & Median & Median $+\sigma$ & Median - $\sigma$ & Median & Median $+\sigma$ \\
\hline Endive / Spinach & 0.56 & $\mathbf{0 . 5 8}$ & 0.60 & 0.25 & $\mathbf{0 . 2 7}$ & 0.29 \\
\hline Head lettuce / Spinach & 0.30 & $\mathbf{0 . 3 1}$ & 0.33 & 0.10 & $\mathbf{0 . 1 1}$ & 0.13 \\
\hline Red oak leaf lettuce / Spinach & & & & 0.32 & $\mathbf{0 . 3 6}$ & 0.42 \\
\hline Endive / Red oak leaf lettuce & 0.54 & $\mathbf{0 . 5 6}$ & 0.59 & & & \\
\hline $\begin{array}{c}\text { Head lettuce / Red oak leaf } \\
\text { lettuce }\end{array}$ & 0.29 & $\mathbf{0 . 3 1}$ & 0.33 & 0.26 & $\mathbf{0 . 2 9}$ & 0.35 \\
\hline Head lettuce / Endive & 054 & $\mathbf{0 . 5 0}$ & 0.59 & 0.38 & $\mathbf{0 . 4 3}$ & 0.46 \\
\hline
\end{tabular}


If we apply the same statistical procedure to the deposition data of ${ }^{131} \mathrm{I}$, we obtain the results given in Fig. $4 \mathrm{~b}$ ) and Table 2. In this case, the deposition to spinach is significantly the highest and the deposition to head lettuce the lowest. Endive and red oak leaf lettuce are in the middle and can not be distinguished statistically in their deposition properties, but they behave significant different as spinach and head lettuce. The following order can be established:

$$
\mathrm{A}_{\text {Spinach }}(1)>\mathrm{A}_{\text {Red oak leaf lettuce }}(0.36)>\mathrm{A}_{\text {Endive }}(0.27)>\mathrm{A}_{\text {Head lettuce }}(0.11) \text {. }
$$

This means that spinach is nearly 3times as highly contaminated as red oak leaf lettuce, 4times as highly as endive and 9time as highly as head lettuce at the same airborne concentration of ${ }^{131} \mathrm{I}$.

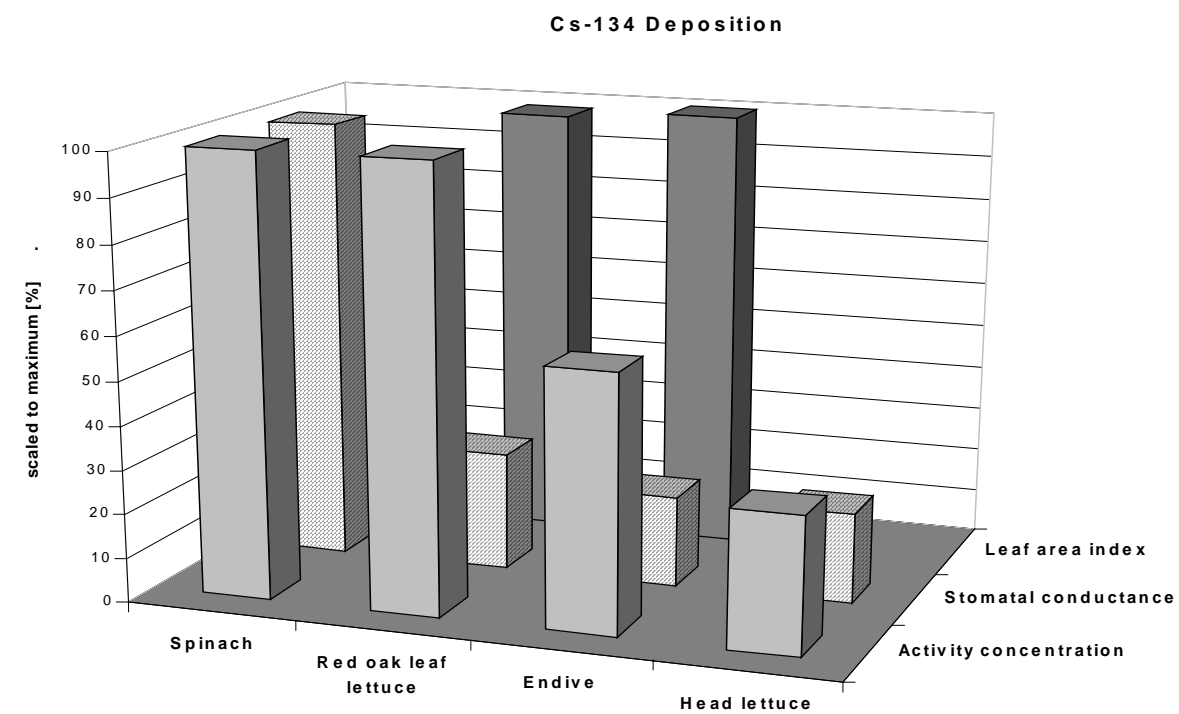

a)

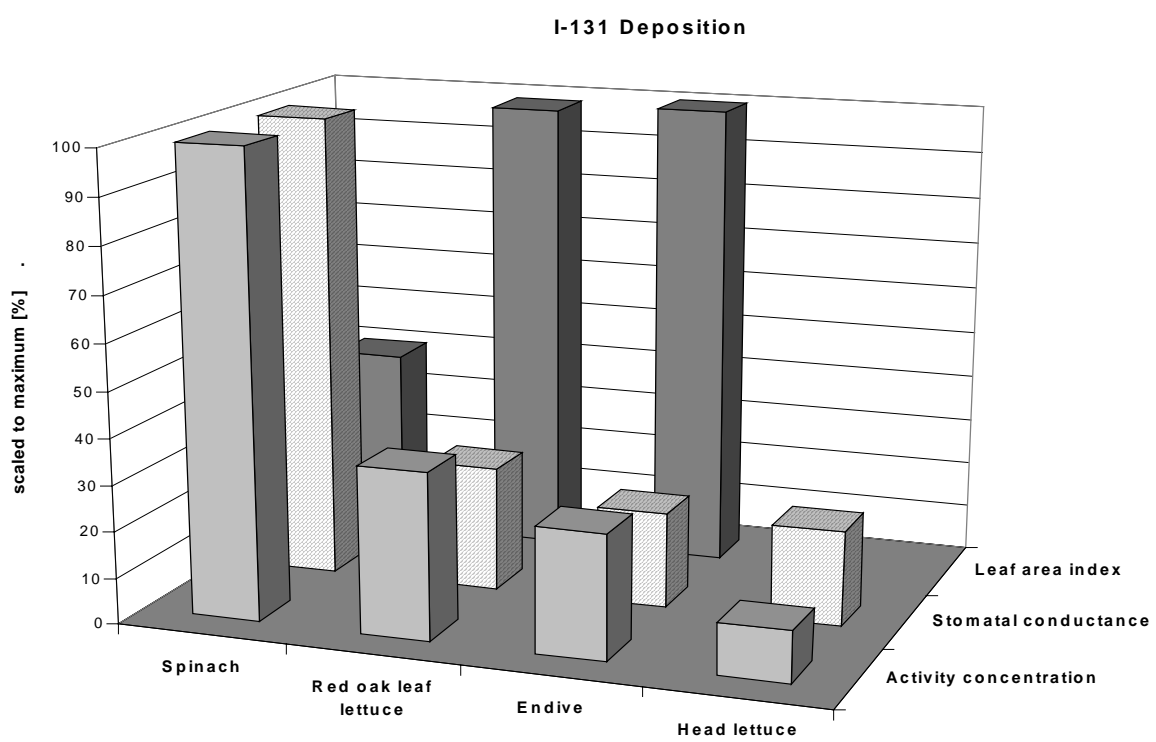

b)

Figure 5. Potential parameters for dry deposition determined for the spring leaf vegetable in comparison to the deposited activity concentration: a) particulate ${ }^{134} \mathrm{Cs}$ and b) gaseous elemental ${ }^{131} \mathrm{I}$. 
The deposition was always the lowest on the closed heads of head lettuce. The rough and structured leafs of red oak leaf lettuce increased the deposition of particulate ${ }^{134} \mathrm{Cs}$. The many open stomata of spinach increased particle deposition but in a much larger extend the deposition of gaseous ${ }^{131}$ I. In Fig. 5 the influence of potential parameters for dry deposition can be compared with the deposited activity concentration. In the case of ${ }^{134} \mathrm{Cs}$ (Fig. 5a), the high activities in spinach correlate with the high stomatal conductance (diffusion of water vapour from the plant leaf), the increased deposition to red oak leaf lettuce correspondences to the leaf area index, but possibly the surface roughness must be considered as well. In the case of ${ }^{131}$ I (Fig. 5b), the deposited activity correlates very good with the measured stomatal conductance of the species. Very striking are the values for spinach which can not be explained with the leaf area index alone.

\section{Acknowledgements}

This study was supported by the Bundesminister für Umwelt, Naturschutz und Reaktorsicherheit of the Federal Republic of Germany under contract StSch 4221. Its contents are solely the responsibility of the authors.

\section{References}

[1] McMahon T.A., Denison P.J., Atmospheric Environment 13, 571-585 (1979).

[2] Nicholson, K.W., Atmospheric Environment 22, 2653-2666 (1988).

[3] Tschiersch J., Georgi B., J. Aerosol Sci. 18, 689-692 (1987).

[4] Watterson J.D., Nicholson K.W., J. Aerosol Sci. 27, 759-767 (1996).

[5] Wedding J.B., Carlson R.W., Stukel J.J., Bazzaz F.A., Environ. Sci. \& Techn. 9, 151-153 (1975).

[6] Heineman K., Vogt K., Health Physics 39, 463-474 (1980).

[7] Nakamura Y., Ohmomo Y., Health Physics 38, 307-314 (1980).

[8] Nakamura Y., Ohmomo Y., Health Physics 38, 315-320 (1980).

[9] Muramatsu M., Uchida S., Sumiya M., Ohmomo Y., Health Physics 71, 757-762 (1996).

[10] Casnati A., Pochini A., Ungano R., Ugozzoli F., Arnaud F., Fanni S., Schwing M.J., Egberink R.J.M., de Jong F., Reinhoudt D. N., J. Am. Chem. Soc. 117, 2767-2777 (1995).

[11] Berner A., Lürzer C., J. Phys. Chem. 84, 2079-2083 (1980).

[12] Shinonaga T., Heuberger, H., Tschiersch, J., in preparation.

[13] Sachs L., Springer Verlag, Berlin, 10. Edition (2002). 